\title{
Análise da satisfação dos usuários das embarcações que aportam no entorno da "Manaus moderna"
}

Daniel Nascimento-e-Silva

Instituto Federal de Educação, Ciência e Tecnologia do Amazonas, Campus Manaus Distrito Industrial, Brasil

ORCID: http://orcid.org/oooo-0oo1-9770-575X

\section{Itarciana do Rego do Rego}

Instituto Federal de Educação, Ciência e Tecnologia do Amazonas, Campus Manaus Distrito Industrial, Brasil

ORCID: http://orcid.org/oooo-0002-0694-8658

Recibido: 15 de octubre de 2019. Aceptado: 27 de mayo de 2020.

\section{Resumo}

As organizações têm como desafio suprir as necessidades de clientes, que exigem níveis de serviços cada vez mais elevados, sem comprometer a viabilidade econômicofinanceira do empreendimento. Níveis de serviços elevados demandam custos elevados, regra que também se aplica ao transporte fluvial de passageiros praticado na Amazônia. Este estudo teve como objetivo analisar a satisfação dos usuários das embarcações amazônicas com o nível de serviço que lhes é oferecido. Utilizou a metodologia de levantamento, cujos dados foram coletados de 408 usuários dos serviços de transporte fornecido pelas embarcações que aportam no porto conhecido por "Manaus Moderna", através de questionários com questões fechadas, analisados com estatísticas descritivas e testes de Kruskal-Wallis e U de Mann-Whitney, para detectar associações das categorias analíticas com aspectos sociodemográficos. Os resultados mostraram que os usuários estão muito satisfeitos com o nível de serviço oferecido, não houve associação entre satisfação e estado civil, gênero e faixa etária e houve diferenças em 14 categorias de satisfação em relação à renda pessoal dos usuários. A conclusão é que a altíssima satisfação dos usuários com o nível de serviço pode ser modificada, caso se lhes altere a renda pessoal, o que revela a fragilidade econômica, financeira e operacional desse meio de transporte que predomina na Amazônia. 


\title{
Analysis of satisfaction of river transport users with the Manaus moderna port service level
}

\begin{abstract}
Organizations are challenged to meet the needs of customers, who demand ever-higher levels of service without compromising the economic and financial viability of the enterprise. High levels of service demand high costs, a rule that also applies to the fluvial passenger transport practiced in the Amazon. This study aimed to analyze the satisfaction of users of Amazonian vessels with the level of service offered to them. It used the survey method, whose data were collected from 408 users of transport services provided by vessels that dock in the port know as Manaus Moderna, through questionnaires with closed questions, analyzed with descriptive statistics and Kruskal-Wallis and Mann-U tests. Whitney, to detect associations of analytical categories with sociodemographic aspects. The results showed that users are very satisfied with the level of service offered, there was no association between satisfaction and marital status, gender and age group and there were differences in 14 satisfaction categories in relation to users' personal income. The conclusion is that the high satisfaction of users with the level of service can be modified if they change their personal income, which reveals the economic, financial and operational fragility of this predominant mode of transport in the Amazon.
\end{abstract}

Keywords: Users satisfaction. Service level. Transportation of passengers. Logistics in the Amazon. Palabras clave: Satisfacción del usuario. Nivel de servicio. Transporte de pasajeros. Logística en la Amazonía.

\section{Introdução}

A Amazônia é uma potência turística muito mal aproveitada (Nascimento e Costa, 2019), evidência que pode ser constatada com o seu principal meio de transporte, as embarcações fluviais. Os rios são as grandes rodovias amazônicas. Talvez essa pouca exploração seja um trunfo ambiental. Uma região onde os demais modais de transportes são escassos ou inexistentes, o aquaviário compõe o grande sistema de distribuição de bens e riquezas regionais. A singularidade amazônica também é construída por dois atributos sórdidos: primeiro, a pobreza que iguala a quase totalidade de seus habitantes, especialmente os de cidades de menores portes; e, segundo, a necessidade de utilizar os precários veículos disponíveis, para levar a produção das cidades menores para as de maior porte, quase sempre na esperança de que a renda ali disponível permita a aquisição daquilo que produzem as cidades menores. Na Amazônia, a sobrevivência quase sempre é produzida nas cidades pequenas, que alimentam as cidades maiores; inversamente, as cidades maiores suprem as demandas por bens industrializados das cidades menores.

Já que não há transporte ferroviário e os modais aéreos e rodoviários são escassos, o primeiro devido ao alto custo das passagens e o segundo em razão da própria geografia regional, onde predomina uma infinidade de rios, o transporte fluvial haveria de imperar. E tem imperado até hoje. Mas, também, o que parece se perpetuar também é a precariedade e a insegurança desse tipo de transporte e o baixo nível de serviço que ali parece também querer se perpetuar. A modernidade, ao que tudo indica, tem se aproximado desse modal com relutância.

Neste sentido, este estudo procurou analisar se os usuários das embarcações estão satisfeitos com o nível de serviço que elas lhes oferecem. A hipótese geral que norteou e orientou este estudo foi de que os usuários só podem estar satisfeitos com o que lhes é oferecido; se não estivessem, provavelmente já teriam migrado para outros tipos de modais logísticos ou forçado a sua oferta, afetando decisivamente o fluxo turístico na região. 
Vários foram os motivos que levaram à realização deste estudo. Destacam-se o esforço de modernização das relações entre transportadores e clientes, melhoria da infraestrutura dos portos, com a introdução de sistemas mecânicos e eletrônicos que reduzam os riscos de acidente e de morte de passageiros, infelizmente ainda muito comuns e as possibilidades de parcerias público-privadas no setor de transporte de passageiros, dentre outras.

Este documento está assim organizado. A primeira parte é essa introdução, seguida da revisão da literatura, onde é definido o fenômeno da satisfação e apontadas suas dimensões e categorias analíticas, depois é detalhado o procedimento metodológico utilizado para gerar os resultados da pesquisa, resultados estes que compõem sua quarta parte. A quinta parte é a conclusão e a sexta é o rol de textos citados.

\section{Satisfação: dimensões e categorias analíticas}

A literatura mostra que a satisfação é um tema complexo e abrangente, porque está vinculado à busca de suprimento das expectativas humanas, ligado a fatores relacionais, infraestruturais e ao produto/serviço. Lizote, Verdinelli, Nascimento (2017) mostram que a satisfação está presente no comportamento organizacional. A satisfação seria a confiança dos consumidores em relação determinado bem estar procurado, o que gera um sentimento prazeroso no indivíduo. A satisfação e a competitividade organizacional estariam relacionadas, materializadas nos trabalhos executados com excelência, envolvendo seus colaboradores e, muitas vezes, até mesmo os indivíduos que buscam suprir suas necessidades durante a execução de serviços, como é o caso dos serviços de transporte fluvial, onde o próprio passageiro ata sua rede, por exemplo.

Pereira e colaboradores (2018) relacionam a satisfação à expectativa do indivíduo decorrente de algum tipo de experiência que tem ou teve que fazer, sobre a qual teve que realizar, produzir ou fazer alguma valorização. Se a expectativa é grande e a realização pequena, é provável que a diferença positiva entre expectativa e a realização seja a satisfação. Isso exige levar em consideração aspectos que podem fazer toda a diferença na realização da satisfação do indivíduo.

Para Vieira (2016), a satisfação está relacionada com o sentimento de prazer. Repousa na visão decorrente de um desempenho pelo menos satisfatório daquilo que se espera. Quando a expectativa é alcançada, o indivíduo fica satisfeito com o serviço prestado, o que gera um sentimento de que o resultado da sua expectativa foi alcançado, sendo positivos os conceitos principais dos sentimentos de prazer. Oliveira, Sales e Brandão (2017) dizem que satisfação significa contentamento com o serviço prestado em relação às expectativas do resultado obtido. É um sentimento de aprovação e satisfação. A satisfação é contentamento do usuário em relação ao produto e aos serviços prestados.

Lima, Silva e Roman (2017) consideram que a satisfação está relacionada com e direcionada pela necessidade de cada indivíduo em relação a seus objetivos. As pessoas sempre estão em busca de melhorias e para isso procuram realizar seus objetivos. Mas nem sempre as coisas acontecem do jeito que elas querem, pois pode haver desapontamentos com algum tipo de procedimento ou serviço que estavam de acordo com o que dele se esperava. $\mathrm{O}$ estudo de Godinho e colaboradores (2017) mostra que a satisfação pode ser definida a partir do grau de expectativa das pessoas. A razão disso é que os clientes temem que suas expectativas sejam supridas ou tratadas com outros meios ou produtos que não desejem, uma vez que esperam por benefício que facilitam suas vidas com qualidade e satisfação.

Lizote, Verdinelli e Nascimento (2017) explicam que a satisfação é a consequência de se ter alcançado determinados objetivos. Isso não quer dizer, contudo, que haja sempre 
resultados dentro do grau de expectativa de indivíduos e organizações. Sabe-se, contudo, que o grau de satisfação é fundamental para a melhoria na eficiência de prestação de serviços à sociedade, que representa algum tipo de expectativa por um resultado, não de decepção, mais de prazer. Isso confirma o estudo de Pereira e colaboradores (2017), que mostra que a satisfação pode ser identificada com o estado emocional e prazeroso do indivíduo.

Vale e colaboradores (2017) também relacionam a satisfação com as expectativas humanas. Mas essas expectativas desempenham uma espécie de princípios e normas, que têm por objetivo planejar, coordenar e controlar os esforços dos indivíduos para o alcance de seus objetivos. Estar satisfeito representa estar em sintonia com os objetivos alcançados. Para Santos e colaboradores (2017), a satisfação está vinculada a evidências, de maneira que produza confiança no desempenho de serviços que foram experimentados e a avaliados positivamente. É essa confiança que vai determinar se determinado serviço (ou produto) tem ou não qualidade, uma vez que qualidade é conformação com as expectativas.

A satisfação é uma forma de prazer que leva em consideração as necessidades humanas (Martins et al., 2017). E o suprimento das necessidades envolve tanto o processo em si, em que se encontram fatores diversos, característico dos serviços, quanto a entrega do produto demandado. Por essa razão, atributos como qualidade do atendimento e experiências de relacionamento proporcionam prazer e permitem, por exemplo, que se estabeleçam relacionamentos duradouros, comumente chamados de fidelização.

A satisfação pode ser vista também como realização (Kruger et al., 2017), enquanto resposta afetiva (Vieira et al., 2017). Como consequência, quando não há a realização ou quando a afetividade não se manifesta conforme esperado, os resultados podem ser até desastrosos, como é o caso do aparecimento da insatisfação ou mesmo da depressão, estágio avançado de insatisfação. Como consequência, para este estudo, a satisfação é um fenômeno psicológico multidimensional que aparece quando a diferença entre a expectativa e a realidade acerca do suprimento de necessidades de um indivíduo é elevada demais para ser suportada. O fenômeno está, portanto, vinculado a um sentimento de prazer em relação determinado resultado esperado (Rodrigues et al., 2017; Rodrigues, 2017).

O estudo de Bastos e Fasolo (2013) descobriu três variáveis que influenciam a satisfação. Dois deles mantiveram relação diretamente proporcional com o fenômeno satisfacional (facilidade de acesso ao serviço médico e o atendimento recebido) e um esteve inversamente associado, o tempo de espera para receber o atendimento. Essas variáveis representam pertencimento a aspectos infraestruturais (facilidade de acesso ao serviço e tempo de espera) e relacionais (atendimento). Os aspectos infraestruturais podem ser todos aqueles que advêm de atividades-meio, que facilitam ou retardam a prestação do serviço, enquanto os relacionais representam a interveniência direta das pessoas e seus relacionamentos para que o serviço possa ser prestado.

González (2005) procurou compreender a fidelidade com serviços de hospedagem. A fidelidade é consequência da satisfação dos clientes em relação a determinados produtos e serviços, de maneira que, quanto maior a satisfação, maior a propensão à fidelidade por parte dos clientes. Os resultados mostraram que cordialidade do pessoal, limpeza, segurança, serviço do restaurante e serviço de internet tiveram comportamento acima do esperado para explicar o fenômeno da fidelização, enquanto qualidade do quarto, cordialidade do pessoal, qualidade do restaurante e preço pago explicaram $56 \%$ da satisfação com o serviço de hospedagem.

Aqui novamente entram em cena a participação de fatores ligados ao relacionamento humano na prestação do serviço, tais como cordialidade do pessoal do hotel e 
cordialidade do pessoal do restaurante, relacionados com a infraestrutura, como é o caso do serviço de internet e serviço do restaurante, quanto com o serviço de hospedagem em si, como é o caso da qualidade do quarto, segurança do hotel e limpeza do hotel. Dessa forma, parece que a satisfação é decorrente de fatores relacionados com o serviço/produto, infraestrutura e de relações humanas.

Esperidião e Trad (2006), estudando a satisfação de usuários de serviços de saúde, mostram que há pelo menos quatro grupos de fatores que explicam a satisfação dos indivíduos. A primeira (mas não a mais importante) são as características sociodemográficas dos indivíduos, assim como as expectativas sobre a consulta médica e o estado de saúde do paciente. A segunda são as características dos profissionais que prestarão o serviço, o que inclui traços de personalidade, qualidade técnica e habilidade no cuidar. A terceira seria decorrente da relação indivíduo-profissionais da prestação de serviço e a quarta seriam fatores estruturais e ambientais, incluindo preço, tempo, forma de pagamento e assim por diante. Nota-se que esses quatro grupos estão contidos na proposição da classificação que propusemos neste estudo, sintetizados em fatores relacionais humanos, infraestruturais e inerentes ao produto/ serviço.

Ferreira (2004) estudou a relação da satisfação e a fidelidade de clientes. Esses pesquisadores reconhecem que a fidelidade é afetada por experiências vividas, emoções, sentimentos, expectativas, percepções e outras variáveis subjetivas; no entanto, para lidar com a fidelidade, seus estudos se concentraram no estudo do que afetam a relação com os clientes, $o$ que implica em dizer, naquilo que provoca a satisfação. Assim, estudaram as características e qualidades do produto, a experiência pessoal do cliente, a qualidade do atendimento na venda, pós-venda e os serviços agregados ao produto e a imagem da empresa e atributos associados à marca do produto. Novamente, aqui os fatores analisados poderiam também ser reagrupados em relacionais, infraestruturais e relativos ao produto/serviço.

Procedimento parecido foi o adotado por Rodrigues (2003) para analisar a relação entre satisfação e fidelidade, cujos constructos estudados foram o valor percebido pelos clientes em relação aos serviços demandados, qualidade percebida, expectativa do cliente, gerenciamento das reclamações, imagem da empresa, comprometimento (afetivo e calculado) e fidelidade do cliente. Novamente a trilogia aqui se repete.

Costa e colaboradores (2018) analisaram a satisfação de indivíduos em relação aos serviços de atenção farmacêutica de determinado estado nordestino a partir de variáveis de três dimensões: infraestrutura, localização e funcionamento; cuidado farmacêutico; e importância do serviço. A primeira dimensão representa o que chamamos fator infraestrutural, que são os serviços de apoio que permitem que os serviços possam ser realizados com adequação ou que o produto possa ser entregue/solicitado com presteza; o atendimento farmacêutico é exemplo de relação humano indivíduo-profissional, essencial na materialização de todo tipo de serviço e que cada vez mais é incorporado nos processos relativos aos produtos; e a importância do serviço toca em questões específicas do serviço ou produto.

A pesquisa de Santos e Sardinha (2017) se concentrou na satisfação dos usuários com os serviços prestados por enfermeiros. Esse estudo foi realizado com a ajuda de um instrumento que continha 25 itens (chamado Instrumento de Satisfação do Paciente) agrupados em três dimensões analíticas. O primeiro eram variáveis que procuravam explicar o domínio do profissional sobre técnicas e conhecimentos considerados essenciais para a prestação do serviço; o segundo foi denominado educacional, no esforço de medir a habilidade para prestar o serviço; enquanto que o terceiro se concentravam em aspectos de interação com o paciente, adequadamente intitulado "domínio confiança", que é o que todo esforço relacional pretende. 
Outro estudo referente à avaliação da qualidade dos serviços de saúde mediu a satisfação dos usuários em relação aos serviços prestados por laboratórios gerais de uma cidade localizada no Sul do Brasil (Beckhauser, 2018). Diversas variáveis foram estudadas, mas as que alcançaram valor explicativo considerado superior foram as dimensões instalações, comunicação, confidencialidade e acesso aos serviços. Já as dimensões serviços complementares disponíveis, disponibilidade de medicamentos, prontidão no atendimento e resultados em termos de saúde mantiveram média avaliativa entre 3 e quadro, a partir de uma escala que variou de 1 a 5 .

Esses estudos parecem confirmar a possibilidade de se agrupar todas as variáveis que interferem de alguma forma na satisfação de clientes e usuários de produtos e serviços de qualquer tipo de organização em três grupos: fatores relacionais, fatores relativos ao produto/serviço e fatores vinculados à infraestrutura, como mostram os dados contidos no quadro 1 . Parece que essa tríade se mantém presente em todo sistema de suprimento de necessidades, que é o que caracterizam as organizações modernas.

Os fatores relacionais respondem por atividades como atendimento, fornecimento de informações, atitudes de compreensão e consolo, dentre toda sorte de interlocução de um indivíduo carente de necessidade a ser suprida e um ou mais indivíduos que se prontificaram em suprir a necessidade percebida. Os fatores infraestruturais englobam todos os tipos de meios necessários para que a prestação do serviço ou suprimento de necessidade possa se efetivar em conformidade com as expectativas tanto de quem demanda quanto de quem realiza o suprimento. Os fatores relativos aos produtos e serviços dizem respeito a todas as características e atributos daquilo que compõe o suprimento demandado pelo cliente ou usuário concentrados no produto solicitado ou serviço contratado.

Quadro 1. Fatores e variáveis influenciadoras da satisfação. Fonte: elaborado pelos autores.

\begin{tabular}{|c|c|}
\hline Autores & Fatores e variáveis influenciadoras \\
\hline Bastos e Fasolo (2013) & $\begin{array}{l}\text { Facilidade de acesso ao serviço, atendimento recebido e tempo de } \\
\text { espera }\end{array}$ \\
\hline González (2005) & $\begin{array}{l}\text { Cordialidade do pessoal, limpeza, segurança, serviço do restaurante, } \\
\text { serviço de internet, qualidade do quarto, qualidade do restaurante e } \\
\text { preço do serviço }\end{array}$ \\
\hline Esperidião e Trad (2006) & $\begin{array}{l}\text { Características sociodemográficas, expectativas e estado de saúde } \\
\text { do indivíduo; características profissionais; relação indivíduo- } \\
\text { profissionais; e fatores estruturais e ambientais. }\end{array}$ \\
\hline Ferreira (2004) & $\begin{array}{l}\text { Características e qualidade do serviço, experiência pessoal do cliente, } \\
\text { qualidade do atendimento, imagem da empresa e atributos do serviço }\end{array}$ \\
\hline Rodrigues (2003) & $\begin{array}{l}\text { Valor percebido, qualidade percebida, expectativa do cliente, } \\
\text { gestão das reclamações, imagem da empresa, comprometimento e } \\
\text { fidelidade. }\end{array}$ \\
\hline Costa et al (2018) & $\begin{array}{l}\text { Infraestrutura, localização e funcionamento; cuidados prestados; } \\
\text { atendimento e importância do serviço }\end{array}$ \\
\hline Santos e Sardinha (2017) & Domínio profissional, domínio educacional, domínio de confiança \\
\hline Beckhauser (2018) & $\begin{array}{l}\text { Serviços prestados, confidencialidade, atendimento, localização, } \\
\text { transporte público, comunicação, instalações, acesso aos serviços, } \\
\text { disponibilidade de medicamentos, serviços complementares, } \\
\text { prontidão no atendimento, atendimento e resultado do serviço }\end{array}$ \\
\hline
\end{tabular}

A satisfação, para este estudo, é o resultado do grau de aproximação entre os atributos de cada um desses fatores efetivamente entregue pelo indivíduo ou organização contratada em relação às expectativas do cliente ou usuário relativamente a cada um desses atributos. Assim, quanto mais distante, menor a satisfação, e quanto menos distante, maior a satisfação. Avaliar a satisfação de clientes ou usuários é aferir qualitativa ou quantitativamente cada variável (também chamada de categoria analítica) de 
forma direta, para que se possa, indiretamente, aferir a satisfação de cada conjunto de variáveis (construtos, fatores ou dimensões analíticas do fenômeno), o que permitirá, por associação, que seja aferida o fenômeno sob investigação.

\section{Metodologia da pesquisa}

Este estudo teve como objetivo avaliar se os usuários das embarcações que compõem o sistema fluvial de transporte de passageiros e que aportam no porto da Manaus Moderna estão satisfeitos com o nível de serviço que lhes é oferecido. Com este intuito é que foi desenhada e operacionalizada a estratégia aqui especificada.

\section{Hipóteses do estudo}

A hipótese global deste estudo, que corresponde à sua hipótese nula, é que os usuários das embarcações estão satisfeitos com o nível de serviço que lhes é oferecido. Como decorrência das análises, foram formuladas as seguintes hipóteses norteadoras:

Hipótese 1: Não há diferença na satisfação com o nível de serviço, quando analisada sob a ótica do estado civil.

Hipótese 2: Não há diferença na satisfação com o nível de serviço, quando feita a comparação entre as faixas etárias.

Hipótese 3: Não há diferença na satisfação com o nível de serviço, quando considerado o gênero dos usuários.

Hipótese 4: Não há diferença na satisfação com o nível de serviço, quando estudado sob a ótica da renda pessoal.

\section{Características do Estudo}

Este é um tipo de estudo quantitativo, que utilizou a metodologia de levantamento (survey, do termo em inglês), e se caracteriza pela busca de respostas para questões de pesquisas que envolvem muitos membros de uma população. Sua preocupação é entender o comportamento de determinado fenômeno a partir de uma amostra para que seja permitida sua generalização através de processos de inferência, especialmente com o uso de ferramentas estatísticas.

A unidade de análise foi individual, uma vez que os indivíduos que já utilizaram alguma vez embarcações para se transportar de determinada cidade para Manaus ou vice-versa foram quem forneceram informações para o estudo. O nível de análise foi organizacional, já que se procurou entender o nível de satisfação em relação a todas as embarcações que aportam no porto da Manaus Moderna, tratadas como um sistema fluvial de transporte de passageiro nesta pesquisa. A perspectiva de análise foi sincrônica, que significa que a intenção dos pesquisadores foi fazer uma espécie de fotografia da realidade, cujos resultados são válidos somente para explicar o fenômeno neste momento, diferente da perspectiva diacrônica, que busca explicar sua dinâmica em diversos momentos dos transcursos históricos.

\section{População e Amostra}

A população foi constituída por todo indivíduo que, alguma vez, utilizou alguma embarcação que aporta no porto da Manaus Moderna como meio de transporte para 
se locomover de Manaus para alguma cidade do interior ou vice-versa. Isso quer dizer que, em termos estatísticos, a população foi considerada infinita, já que provavelmente ninguém sabe ao certo quantos indivíduos se enquadram nessa categoria (Silva et al., 2018; Dallazen et al., 2018; Mondo, Hallmann e Burg, 2018), sendo constituídos provavelmente por dezenas e talvez centenas de milhares de pessoas, já que os barcos são o principal meio de transporte regional.

A amostra foi calculada com base na fórmula $\mathrm{TA}=1 / \mathrm{E} 2$, onde TA é o tamanho da amostra e E é a margem de erro máximo admitido para o estudo, tendo como referência o nível de significância de $95 \%$. A aplicação da fórmula resultou na necessidade de se coletar dados de 400 indivíduos. No entanto, estabeleceu-se um percentual de 20 questionários a mais, correspondentes a 5\% do total, para efeitos de precaução na hipótese de se ter que descartar algum deles por algum motivo, tais como preenchimento incorreto, rasuras e marcações em desconformidade com o protocolo do estudo. Dos 420 questionários submetidos, 408 foram considerados válidos para a análise e geração dos resultados.

\section{Instrumento de Coleta de Dados}

Em conformidade com o marco teórico, o questionário foi o instrumento escolhido para coletar os dados deste estudo, principalmente porque é o meio mais viável e rápido para consultar uma amostra grande no menor espaço de tempo possível. O instrumento estava dividido em duas partes: a primeira dizia respeito aos aspectos sociodemográficos dos respondentes, enquanto a segunda se concentrava nas dimensões e categorias de análise do estudo.

Foram escolhidas cinco categorias sociodemográficas para estudo, em conformidade com as hipóteses de trabalho, secundárias, do estudo: estado civil, faixa etária, sexo e renda mensal pessoal. Vale ressaltar que o questionário iniciava com uma questão de controle, que procurava certificar se o respondente já tinha utilizado alguma embarcação para se locomover de uma cidade para outra, condição necessária para fazer parte da população do estudo.

Quadro 2. Categorias e dimensões analíticas do estudo. Fonte: elaborado pelos autores.

\begin{tabular}{|l|l|}
\hline Dimensões Analíticas & Categorias Analíticas \\
\hline Relacionais & $\begin{array}{l}\text { Atendimento pelos funcionários } \\
\text { Rapidez do pessoal na solução de problemas } \\
\text { Cordialidade dos funcionários } \\
\text { Acesso ao comandante/responsável pela embarcação }\end{array}$ \\
\hline Infraestruturais & $\begin{array}{l}\text { Facilidade para comprar a passagem } \\
\text { Segurança no embarque/desembarque } \\
\text { Segurança durante a viagem } \\
\text { Facilidade para chegar à embarcação no porto } \\
\text { Cumprimento do horário de partida } \\
\text { Cumprimento do horário de chegada }\end{array}$ \\
\hline Relativas ao Serviço & $\begin{array}{l}\text { Climatização da embarcação } \\
\text { Qualidade do armador/camarote } \\
\text { Preço da passagem } \\
\text { Preço do transporte de bagagem } \\
\text { Qualidade da alimentação } \\
\text { Limpeza do local de dormir } \\
\text { Limpeza dos banheiros } \\
\text { Limpeza do local de alimentação }\end{array}$ \\
\hline
\end{tabular}

As questões explicativas foram organizadas em três dimensões: relacionais, infraestruturais e relativas ao serviço, conforme mostra o quadro 2. Assim, foram escolhidas 
4 categorias relacionais, 6 infraestruturais e 8 relativas ao serviço de transporte de passageiros. As categorias foram escolhidas com base em levantamento prévio feito a uma pequena amostra de passageiros, cuja finalidade foi identificar o que consideravam importante que uma embarcação precisava apresentar para que pudessem se considerar satisfeitos ou insatisfeitos com os serviços de transportes.

\section{Estratégia de coleta dos dados}

Os dados foram coletados durante 10 dias seguidos, iniciando-se em uma sexta-feira e terminando no domingo seguinte. Essa decisão levou em consideração o fato de que os dias de sexta a domingo são os escolhidos para que as embarcações partam de Manaus em direção às cidades de destino dos passageiros, momento em que os passageiros estariam mais disponíveis para serem abordados. Além disso, seria possível consultar passageiros de embarcações que, na primeira semana, não estariam disponíveis, uma vez que há destinos que levam 15 dias para que a embarcação parta para a cidadedestino e retorne ao porto da Manaus Moderna.

Os dados foram coletados no perímetro que vai da ponte de Educandos até o início do Porto de Manaus, conhecido como Rodway, de aproximadamente 1,5 quilômetro. Todos os dias os pesquisadores abordavam os passageiros que chegavam ou saíam, até que o total de questionários previstos no cálculo da amostragem fosse completamente esgotado, o que coincidiu, conforme programado, com o décimo dia de coleta de dados.

Os potenciais informantes eram abordados, momento em que lhes era explicado o motivo do estudo, como deveria ser o procedimento de preenchimento e lhes era perguntado se gostariam de participar. Caso positivo, o questionário lhe era repassado, esperando-se o término do preenchimento e recolhimento, e quando o respondente não sabia ler, os pesquisadores faziam a leitura e marcavam a resposta fornecida.

\section{Procedimento de Organização e Análise dos Dados}

Depois de preenchidos, os questionários analisados, item a item, para saber se as respostas não apresentavam rasuras, mais de uma marcação ou se estavam em branco. Neste procedimento foram descartados 12 questionários. Depois, os restantes foram transcritos para uma planilha eletrônica, onde cada resposta foi transformada em número, em conformidade com a resposta marcada pelo respondente. Resposta em que foi marcada a primeira alternativa correspondia ao número 1; se fosse marcada a terceira alternativa, o número anotado na planilha seria o 3; e assim por diante.

Os dados da planilha foram exportados para o SPSS (Statistics Package for Social Sciences). Primeiro foram geradas as estatísticas sumárias, contidas em tabelas, relativas aos aspectos sociodemográficos da amostra. Em seguida foi feito o teste de normalidade, com o uso dos testes de Kolmogorov-Smirnov e Shapiro-Wilk, sempre com nível de significância de $95 \%$, para saber se os dados poderiam ou não ser considerados paramétricos, normais, o que implicaria, se não fossem normais, na rejeição da média como medida de tendência central e sua substituição pela mediana. Também foram calculados os desvios padrões de cada categoria analítica, de maneira que se pudesse aferir o nível de satisfação dos respondentes em relação ao nível de serviço que as embarcações praticam.

Uma vez que a mediana é a medida que sintetiza o comportamento da categoria, o desvio padrão calculado para cada variável explica se aquele comportamento pode ser considerado consensual ou não, dependendo de sua aproximação ou distância de zero. De posse da mediana e desvio padrão foi analisada a situação global do nível de serviço das embarcações pesquisadas. 
Depois buscou-se saber se aquele resultado estava ou não associado com as categorias sociodemográficas escolhidas. Para testar a hipótese de que não há diferença de satisfação a com o nível de serviço segundo o estado civil, faixa etária e renda, foi utilizado o teste de Kruskal-Wallis de amostras independentes, enquanto para testar a hipótese de que a satisfação não está associada com o gênero dos respondentes foi utilizado o teste U de Mann-Whitney. Foi analisada a significância com margem de erro de 5\% para a interpretação dos resultados.

\section{Resultados da pesquisa}

Este estudo buscou analisar se os usuários do sistema de transporte fluvial de passageiros estão satisfeitos com o nível de serviço que lhe são oferecidos. Os resultados estão aqui organizados em dois blocos. O primeiro bloco apresenta um detalhamento da amostra utilizada, enquanto o segundo se concentra sobre as hipóteses que orientaram os estudos empíricos, a partir do marco teórico construído especificamente para este fim.

\section{Características demográficas}

A maior parte dos usuários dos serviços de transportes ofertados pelas embarcações pesquisadas é solteira, com 44,7\%. Em segundo lugar aparecem os casados, com 32,2\%. Os viúvos, os que mantêm relacionamento de união estável e outros estados civis compuseram, respectivamente, 7,6\%, 8,1\% e 7,4\%, da amostra utilizada. Estes três últimos estados representaram $23,1 \%$ do total de usuários pesquisados nesta investigação.

Há a predominância de usuários que não têm relacionamento conjugal, se somados os solteiros com os viúvos, com o total de $52,3 \%$, contra $40,3 \%$ de casados e mantenedores de relacionamento de união estável. Isso significa que, do ponto de vista logístico, a composição dos itens do nível de serviço de transporte deve privilegiar os usuários solteiros. Como muitos usuários do sistema mantém relacionamento conjugal, seria importante averiguar a possibilidade de composição dos itens de serviços também com as suas necessidades, de maneira que possa contemplar as quatro categorias de estado civil.

Quando analisados sob o ponto de vista da faixa etária, os usuários do sistema de transporte fornecidos pelas embarcações apresentam uma distribuição praticamente uniforme. Os indivíduos com menos de 30 anos representam $45,8 \%$ de todos os viajantes, sendo que $21,3 \%$ têm menos de 20 anos de idade. Se somados os jovens (menos de 30 anos) com os jovens adultos (entre 30 e 40 anos), o total é de $69,1 \%$ de todos os usuários. Os adultos plenos e demais estratos representam os 30,1\% restantes, praticamente um terço, sendo que os que disseram ter 50 anos ou mais representam apenas $12,5 \%$ do total de respondentes do estudo.

Esses resultados são significativos para a composição do nível de serviços porque, dada a distribuição equilibrada entre os estratos de maiores frequência, força os gestores das embarcações a contemplar e atender diferentes necessidades. Como praticamente $70 \%$ é de jovens e jovens adultos, o mais recomendado seria direcionar seus esforços para esse contingente, sabendo-se, porém, que praticamente um terço dos usuários estaria fora desse foco.

As mulheres representam o maior contingente de usuários do sistema de transporte de passageiros por embarcações pesquisado. O contingente feminino alcançou 52,7\%, contra $47,3 \%$ dos usuários do sexo masculino. Do ponto de vista estatístico, porém, a diferença verificada se encontra dentro da margem de erro, que é de 5\%. 
Há equilíbrio entre homens e mulheres nas viagens de barco dentre as embarcações que utilizam o porto da Manaus Moderna. Como os usuários utilizam esse sistema de transporte por motivos diversos, talvez essa diversidade faça parte da realidade presente de homens e mulheres, diferentemente do passado mais distante, em que predominavam os homens. Talvez as usuárias mulheres estejam, pouco a pouco, sobrepujando a supremacia masculina na demanda por esse tipo de transporte.

Uma das descobertas interessantes desse estudo empírico foi a constatação de que dois terços $(67,4 \%)$ dos usuários das embarcações disseram ter renda pessoal menor que $\mathrm{R} \$ 1.000,00$ reais e $85,3 \%$ têm renda pessoal inferior a $\mathrm{R} \$ 1.500,00$, como mostram os dados contidos na tabela 4 . Aliás, $94,4 \%$ de todos os passageiros pesquisados ganham menos que $\mathrm{R} \$ 2.000,00$ mensais e apenas 5,6\% deles disseram ganhar mais do que isso, como mostra o quadro 3 .

Quadro 3. Respondentes, por renda. Fonte: elaborado pelos autores.

\begin{tabular}{|l|c|c|c|}
\hline Categorias & Frequência & $\%$ & \% acumulada \\
\hline Menos de 500 & 162 & 39,7 & 39,7 \\
\hline 500 a 999 & 113 & 27,7 & 67,4 \\
\hline 1.000 a 1.499 & 73 & 17,9 & 85,3 \\
\hline 1.500 a 1.999 & 37 & 9,1 & 94,4 \\
\hline 2.000 ou mais & 23 & 5,6 & 100,0 \\
\hline Total & 408 & 100,0 & \\
\hline
\end{tabular}

Nível de significância de 95\%.

A população pobre ou menos aquinhoada financeiramente é a que utiliza os serviços de transportes de passageiros por embarcações. Talvez seja essa população que procura a capital do Amazonas em busca de serviços de saúde, por exemplo, que são extremamente precários ou até mesmo inexistentes nas pequenas cidades do interior, uma vez que até mesmo as cidades de porte médio esses serviços são deficientes. Da mesma forma, é provável que aportem na cidade em busca da venda dos produtos que trazem consigo em pequena monta ou que, inversamente, venham para adquirir produtos para serem revendidas nas suas cidades do interior. Necessidades socioeconômicas talvez expliquem a predominância da população pobre como demandantes predominantes desses serviços.

\section{Testes de confiabilidade e normalidade}

O teste de confiabilidade realizado foi o alfa de Cronbach, que alcançou 0,880, mas que, com os itens padronizados, alcançou o valor de 0,913 , considerado altamente capaz de garantir a confiança que o estudo requer. $O$ segundo teste a que foi submetida a amostra utilizada neste estudo foi o de normalidade. A razão é bastante simples: saber que tipo de testes de hipóteses dever-se-ia utilizar para alcançar os objetivos desta investigação. $\mathrm{O}$ teste de normalidade se presta justamente para isso: saber se os dados coletados apresentam ou não um comportamento normal. Se o comportamento for normal, o recomendado é que sejam utilizados testes estatísticos centrados na média; se os dados não apresentarem comportamento normal, os testes a serem utilizados serão centrados na mediana, os chamados não paramétricos. 
Quadro 4. Teste de normalidade dos dados. Fonte: elaborado pelos autores.

\begin{tabular}{|c|c|c|c|c|c|c|}
\hline & \multicolumn{3}{|c|}{ Kolmogorov-Smirnova } & \multicolumn{3}{|c|}{ Shapiro-Wilk } \\
\hline & Estatística & gl & Sig. & Estatística & gl & Sig. \\
\hline Atendimento pelos funcionários & 0,219 & 407 & , ০oo & 0,816 & 407 & , ००० \\
\hline Rapidez na resolução de problemas & 0,203 & 407 & , o०o & 0,839 & 407 & , 000 \\
\hline Cordialidade dos funcionários & 0,162 & 407 & , ০oo & 0,882 & 407 & , 0०० \\
\hline Acesso ao comandante/responsável & 0,308 & 407 & , ০oo & 0,368 & 407 & , ००० \\
\hline Climatização da embarcação & 0,330 & 407 & , ০oo & 0,346 & 407 & , ००० \\
\hline Qualidade do armador/camarote & 0,156 & 407 &, 000 & 0,904 & 407 & , 0०० \\
\hline Preço da passagem & 0,170 & 407 & , & 0,900 & 407 & , o०o \\
\hline Preço do transporte de bagagem & 0,163 & 407 & , ০oo & 0,900 & 407 & , ००० \\
\hline Qualidade da alimentação & 0,155 & 407 & , ০oo & 0,901 & 407 & , 0oo \\
\hline Limpeza do local de dormir & 0,150 & 407 &, 000 & 0,900 & 407 & ,000 \\
\hline Limpeza dos banheiros & 0,156 & 407 & , ০oo & 0,903 & 407 & , 0oo \\
\hline Limpeza do local das refeições & 0,168 & 407 & , ০oo & 0,888 & 407 & , o०o \\
\hline Facilidade para comprar a passagem & 0,325 & 407 & , ০oo & 0,356 & 407 & , 0०० \\
\hline $\begin{array}{l}\text { Segurança no embarque/ } \\
\text { desembarque }\end{array}$ & 0,201 & 407 & , o०o & 0,859 & 407 & ,000 \\
\hline Segurança durante a viagem & 0,200 & 407 & , o०o & 0,855 & 407 & , 0०o \\
\hline Facilidade para chegar à embarcação & 0,206 & 407 &, 000 & 0,851 & 407 & , ००० \\
\hline Cumprimento do horário de partida & 0,218 & 407 &, 000 & 0,845 & 407 & , ০oo \\
\hline Cumprimento do horário de chegada & 0,206 & 407 &, 000 & 0,839 & 407 & , ০oo \\
\hline
\end{tabular}

Os resultados contidos no quadro 4 mostram que todas as variáveis apresentaram comportamento não normal, uma vez que os p-values alcançaram nível de significância menor que 0,05, o que leva à rejeição da hipótese nula, de que os dados seriam normais. Isso significa que os testes de hipóteses a serem aplicados deverão ter a mediana como referência, em detrimento da média, utilizada para dados considerados normalizados.

\section{Análise da satisfação global dos usuários}

O quadro 5 sintetiza a satisfação dos usuários do sistema de transporte fluvial estudado. Constatou-se que todas as variáveis pesquisadas encontraram alto grau de satisfação por parte dos entrevistados, destacando-se a avaliação do atendimento prestado pelos funcionários, que obteve mediana igual a 9 e desvio padrão (DP) igual a 0,1 , o que significa, na prática, consenso de que o atendimento recebido é excelente. 
Quadro 5. Satisfação Global dos Usuários. Fonte: elaborado pelos autores.

\begin{tabular}{|l|c|c|c|}
\hline Variáveis & Mediana & DP & Mediana -2DP / +2DP \\
\hline Atendimento pelos funcionários & 9 & 0,1 & $8,8 / 9,2$ \\
\hline Rapidez na resolução de problemas & 8 & 0,1 & $7,8 / 9,2$ \\
\hline Cordialidade dos funcionários & 8 & 0,1 & $7,8 / 9,2$ \\
\hline Acesso ao comandante/responsável & 8 & 0,1 & $7,8 / 9,2$ \\
\hline Climatização da embarcação & 8 & 0,3 & $7,4 / 8,6$ \\
\hline Qualidade do armador/camarote & 7 & 0,1 & $6,8 / 7,2$ \\
\hline Preço da passagem & 7 & 0,1 & $6,8 / 7,2$ \\
\hline Preço do transporte de bagagem & 7 & 0,1 & $6,8 / 7,2$ \\
\hline Qualidade da alimentação & 7 & 0,1 & $6,8 / 7,2$ \\
\hline Limpeza do local de dormir & 7 & 0,1 & $6,8 / 7,2$ \\
\hline Limpeza dos banheiros & 7 & 0,1 & $6,8 / 7,2$ \\
\hline Limpeza do local das refeições & 7 & 0,1 & $6,8 / 7,2$ \\
\hline Facilidade para comprar a passagem & 8 & 0,3 & $7,4 / 8,6$ \\
\hline Segurança no embarque/desembarque & 8 & 0,1 & $7,8 / 9,2$ \\
\hline Segurança durante a viagem & 8 & 0,1 & $7,8 / 9,2$ \\
\hline Facilidade para chegar à embarcação & 8 & 0,1 & $7,8 / 9,2$ \\
\hline Cumprimento do horário de partida & 8 & 0,1 & $7,8 / 9,2$ \\
\hline Cumprimento do horário de chegada & 8 & 0,1 & $7,8 / 9,2$ \\
\hline
\end{tabular}

Além disso, 10 outras variáveis alcançaram a mediana 8 e sete chegaram a 7 como avaliação global. Vale ressaltar, contudo, que o desvio padrão sempre foi extremamente baixo, em torno do valor 0,1 , com exceção da variável "climatização da embarcação", que teve o valor 0,3, ainda assim um valor baixíssimo. Quanto mais baixo o desvio padrão, portanto, maior o grau de consenso de que o valor da mediana representa, de verdade, a avaliação do grau de satisfação com a variável medida.

Esses resultados demonstram que a população que demanda os serviços de transporte está muito satisfeita com o nível de serviço que lhe é oferecido. Em termos práticos, a menor nota que alguém poderia dar para as variáveis pesquisadas seria 6,8, em uma escala de 0 a 10 . Neste estudo, as notas 6,8 recaíram justamente sobre a qualidade do armador ou camarote, o preço da passagem e do transporte de bagagem, a qualidade da alimentação e da limpeza (do local de dormir, banheiros e do local de refeição). Mas essa menor nota ainda é uma nota muito alta, o que demonstra o alto grau de satisfação desses usuários.

\section{Análise da satisfação, por estado civil}

A premissa básica da hipótese aqui testada é que não há diferença na satisfação dos usuários do sistema de transporte de passageiros, se considerado o estado civil dos respondentes. Isso significa que não há associação entre o estado civil e a satisfação dos passageiros. Para testar a hipótese foi utilizado o teste de Kruskal-Wallis de amostras independentes. Os resultados obtidos, constantes no quadro 6, mostram que a hipótese nula é verdadeira, que não há diferença na satisfação dos usuários, segundo o estado civil, com exceção da variável "Acesso ao comandante/responsável" da embarcação. 
Quadro 6. Satisfação, por estado civil. Fonte: elaborado pelos autores.

\begin{tabular}{|l|c|c|}
\hline Variáveis & Significância & Decisão \\
\hline Atendimento pelos funcionários & 0,051 & Não há diferença \\
\hline Rapidez na resolução de problemas & 0,118 & Não há diferença \\
\hline Cordialidade dos funcionários & 0,083 & Não há diferença \\
\hline Acesso ao comandante/responsável & 0,037 & Há diferença \\
\hline Climatização da embarcação & 0,080 & Não há diferença \\
\hline Qualidade do armador/camarote & 0,276 & Não há diferença \\
\hline Preço da passagem & 0,497 & Não há diferença \\
\hline Preço do transporte de bagagem & 0,121 & Não há diferença \\
\hline Qualidade da alimentação & 0,097 & Não há diferença \\
\hline Limpeza do local de dormir & 0,308 & Não há diferença \\
\hline Limpeza dos banheiros & 0,286 & Não há diferença \\
\hline Limpeza do local das refeições & 0,104 & Não há diferença \\
\hline Facilidade para comprar a passagem & 0,182 & Não há diferença \\
\hline Segurança no embarque/desembarque & 0,223 & Não há diferença \\
\hline Segurança durante a viagem & 0,572 & Não há diferença \\
\hline Facilidade para chegar à embarcação & 0,566 & Não há diferença \\
\hline Cumprimento do horário de partida & 0,202 & Não há diferença \\
\hline Cumprimento do horário de chegada & 0,584 & Não há diferença \\
\hline
\end{tabular}

Esses resultados indicam que o estado civil não interfere na satisfação dos passageiros. Na prática, usuários solteiros, casados, viúvos, com união estável ou qualquer outro têm o mesmo grau de satisfação, de maneira que sua satisfação é indiferente, está além do fato de manter ou não um relacionamento, estável ou passageiro. Isso influencia, naturalmente, na composição do nível de serviços oferecidos pela embarcação, que terá uma preocupação a menos na escolha dos itens que deverá escolher para oferecer aos seus clientes.

\section{Análise da satisfação, por faixa etária}

Procurou-se saber se há diferença na satisfação dos passageiros das embarcações pesquisadas, segundo a sua faixa etária. O pressuposto básico foi que não há diferença, que previa a hipótese nula. Para testar essa hipótese utilizou-se o teste de KruskalWallis de amostras independentes. A hipótese alternativa previa que haveria diferença na satisfação dos indivíduos pesquisados. Os resultados estão contidos no quadro 7.

Quadro 7. Satisfação, por faixa etária. Fonte: elaborado pelos autores.

\begin{tabular}{|l|c|c|}
\hline Variáveis & Significância & Decisão \\
\hline Atendimento pelos funcionários & 0,742 & Não há diferença \\
\hline Rapidez na resolução de problemas & 0,527 & Não há diferença \\
\hline Cordialidade dos funcionários & 0,460 & Não há diferença \\
\hline Acesso ao comandante/responsável & 0,720 & Não há diferença \\
\hline Climatização da embarcação & 0,341 & Não há diferença \\
\hline Qualidade do armador/camarote & 0,775 & Não há diferença \\
\hline Preço da passagem & 0,639 & Não há diferença \\
\hline Preço do transporte de bagagem & 0,972 & Não há diferença \\
\hline Qualidade da alimentação & 0,272 & Não há diferença \\
\hline Limpeza do local de dormir & 0,723 & Não há diferença \\
\hline
\end{tabular}




\begin{tabular}{|l|c|c|}
\hline Variáveis & Significância & Decisão \\
\hline Limpeza dos banheiros & 0,492 & Não há diferença \\
\hline Limpeza do local das refeições & 0,530 & Não há diferença \\
\hline Facilidade para comprar a passagem & 0,420 & Não há diferença \\
\hline Segurança no embarque/desembarque & 0,766 & Não há diferença \\
\hline Segurança durante a viagem & 0,976 & Não há diferença \\
\hline Facilidade para chegar à embarcação & 0,979 & Não há diferença \\
\hline Cumprimento do horário de partida & 0,548 & Não há diferença \\
\hline Cumprimento do horário de chegada & 0,944 & Não há diferença \\
\hline
\end{tabular}

A satisfação não varia conforme a idade dos usuários do sistema de transporte de passageiros pesquisado. Não há diferença, portanto, na satisfação dos indivíduos pesquisados, segundo essa categoria demográfica, o que representa, também, um desafio a menos para os gestores das embarcações manterem elevado o nível de satisfação que este estudo detectou.

\section{Análise da satisfação, por gênero}

Outra hipótese testada foi a que previa que não havia diferença entre a satisfação dos homens e a satisfação das mulheres que viajam pelas embarcações em estudo, configurando sua hipótese nula. A hipótese alternativa dizia o contrário, que havia diferença. $\mathrm{O}$ teste utilizado foi o U de Mann-Whitney, cujos resultados estão contidos no quadro 8 .

Quadro 8. Satisfação, por Gênero. Fonte: elaborado pelos autores.

\begin{tabular}{|l|c|c|}
\hline Variáveis & Significância & Decisão \\
\hline Atendimento pelos funcionários & 0,460 & Não há diferença \\
\hline Rapidez na resolução de problemas & 0,794 & Não há diferença \\
\hline Cordialidade dos funcionários & 0,509 & Não há diferença \\
\hline Acesso ao comandante/responsável & 0,338 & Não há diferença \\
\hline Climatização da embarcação & 0,023 & Há diferença \\
\hline Qualidade do armador/camarote & 0,103 & Não há diferença \\
\hline Preço da passagem & 0,205 & Não há diferença \\
\hline Preço do transporte de bagagem & 0,991 & Não há diferença \\
\hline Qualidade da alimentação & 0,622 & Não há diferença \\
\hline Limpeza do local de dormir & 0,834 & Não há diferença \\
\hline Limpeza dos banheiros & 0,487 & Não há diferença \\
\hline Limpeza do local das refeições & 0,486 & Não há diferença \\
\hline Facilidade para comprar a passagem & 0,766 & Não há diferença \\
\hline Segurança no embarque/desembarque & 0,571 & Não há diferença \\
\hline Segurança durante a viagem & 0,834 & Não há diferença \\
\hline Facilidade para chegar à embarcação & 0,623 & Não há diferença \\
\hline Cumprimento do horário de partida & 0,860 & Não há diferença \\
\hline Cumprimento do horário de chegada & 0,677 & Não há diferença \\
\hline
\end{tabular}

Há diferença de satisfação, entre homens e mulheres, apenas em relação à variável "climatização da embarcação". As demais variáveis apontaram homogeneidade de satisfação entre os respondentes de ambos os sexos. Novamente, aqui se verifica a possibilidade de que os serviços prestados pelos gestores de embarcações têm conseguido satisfazer as necessidades de homens e mulheres, de maneira que a avaliação elevada se mantém para cada um dos segmentos de gênero. 


\section{Análise da satisfação, por renda}

A renda foi outra categoria demográfica utilizada para detectar possíveis diferenças de satisfação entre os usuários das embarcações pesquisadas. A hipótese nula dizia que não haveria diferença na satisfação, se analisada sob a ótica dos rendimentos mensais pessoais dos indivíduos pesquisados; a hipótese alternativa afirmava que haveria diferença. Para testar a hipótese foi utilizado o teste de Kruskal-Wallis de amostras independentes e os resultados estão contidos no quadro 9.

Quadro 9. Satisfação, por renda. Fonte: elaborado pelos autores.

\begin{tabular}{|l|c|c|}
\hline Variáveis & Significância & Decisão \\
\hline Atendimento pelos funcionários & 0,000 & Há diferença \\
\hline Rapidez na resolução de problemas & 0,000 & Há diferença \\
\hline Cordialidade dos funcionários & 0,024 & Há diferença \\
\hline Acesso ao comandante/responsável & 0,004 & Há diferença \\
\hline Climatização da embarcação & 0,001 & Há diferença \\
\hline Qualidade do armador/camarote & 0,118 & Não há diferença \\
\hline Preço da passagem & 0,011 & Há diferença \\
\hline Preço do transporte de bagagem & 0,212 & Não há diferença \\
\hline Qualidade da alimentação & 0,001 & Há diferença \\
\hline Limpeza do local de dormir & 0,002 & Há diferença \\
\hline Limpeza dos banheiros & 0,041 & Há diferença \\
\hline Limpeza do local das refeições & 0,014 & Há diferença \\
\hline Facilidade para comprar a passagem & 0,399 & Não há diferença \\
\hline Segurança no embarque/desembarque & 0,103 & Não há diferença \\
\hline Segurança durante a viagem & 0,001 & Há diferença \\
\hline Facilidade para chegar à embarcação & 0,000 & Há diferença \\
\hline Cumprimento do horário de partida & 0,002 & Há diferença \\
\hline Cumprimento do horário de chegada & 0,006 & Há diferença \\
\hline
\end{tabular}

Isso mostra que há, sim, diferença na satisfação dos usuários das embarcações, segundo a categoria demográfica renda. $\mathrm{O}$ estudo mostra que os indivíduos só têm satisfação parecida em relação à "qualidade do armador/camarote", "preço do transporte de bagagem", "facilidade para comprar a passagem" e "segurança no embarque/desembarque"; nas demais variáveis, portanto, a satisfação é diferente. Isso significa que as pessoas que têm a renda um pouco mais elevada veem de forma diferente a maioria das variáveis que compuseram o instrumento de coleta de dados desta pesquisa.

Esses resultados são muito importantes, do ponto de vista gerencial e logístico, porque sinalizam aos gestores de embarcações que variações na renda dos indivíduos que demandam seus serviços podem migrar para outros tipos de modais, se disponíveis, como é o caso do aeroviário. Talvez a elevação do nível de serviço, para contemplar esse segmento mais exigente, além de manter elevada a satisfação do segmento mais abonado financeiramente poderia reduzir a diferença de satisfação aqui detectada.

\section{Conclusão}

Este estudo mostrou que os usuários das embarcações que aportam no porto da Manaus Moderna estão satisfeitos com o nível de serviço que lhe é oferecido. Constatou-se, 
também, que essa satisfação não é afetada pelo estado civil, gênero e faixa etária dos usuários, mas foram detectadas diferenças de posições sobre a satisfação em relação à renda pessoal, ou seja, quanto maior a renda do indivíduo que usa as embarcações como meio de transporte, menos satisfeito ele está com o nível de serviço que lhe é oferecido. A flutuação do nível de renda pode afetar o fluxo turístico por esse modal.

A renda das pessoas que utilizam os serviços de transporte de passageiros na Amazônia é muito baixa. Apenas 5,6 disseram ganhar mais do que dois mil reais por mês, sendo que $40 \%$ disseram ganhar menos que 500 reais mensais. Com renda nesse nível, qualquer diferença no preço do transporte se torna atrativo para eles. Às vezes até mesmo diferença de centavos os faz mudar de transportador, como acontece com as tarifas praticadas para as linhas de transporte para municípios muito próximos de Manaus, em torno de menos de dez reais por trecho. Vale informar, por exemplo, que com um real é possível pagar uma "merenda", que consiste em um salgado e um pequeno copo de suco, vendas muito comuns nos portos populares.

Esses resultados parecem indicar que há sensibilidade dos usuários em relação ao preço praticado pelos serviços de transporte. As embarcações que aportam no Rodway são de maiores portes que as aqui analisadas, com mais infraestrutura e usam mais tecnologias. Mas quando há a redução do preço de suas tarifas, uma parte dos usuários dos transportes de embarcações que aportam na Manaus Moderna migram para lá. Fenômeno parecido acontece com as tarifas de transporte aéreo: quando baixam bastante, tornam-se próximas das tarifas praticadas por essas embarcações, principalmente para Santarém, Belém e Porto Velho. A redução no preço da tarifa dos serviços de transportes de passageiros considerados superiores e do transporte aéreo atraem os usuários dos considerados inferiores.

Como esse é um sistema que supre necessidades das populações amazônicas mais pobres, o transporte por embarcações tende a perpetuar uma tradição histórica e que talvez as poucas melhorias que sofreram ao longo de décadas, como é o caso de climatização no ambiente de dormida, sejam suficientes para superar suas expectativas com os serviços oferecidos. Mas isso provavelmente não é o suficiente para manter a satisfação de quem dispõe de um pouco mais de renda, o que explica os níveis mais elevados de exigência para que sua satisfação seja garantida.

Esses resultados se convertem em desafios para os gestores das embarcações, uma vez que precisam dar conta de incorporação ou transformação dos itens que compõem o nível de serviço atual para patamares mais elevados, de maneira que possam manter fiéis os usuários já contentes e elevar a satisfação dos que têm satisfação não tão elevada e fiéis como os demais. Evidentemente que essas alterações e até mesmo transformações não podem elevar o custo médio dos serviços, o que poderia impedir a população mais pobre de continuar demandando o transporte fluvial de passageiros das cidades amazônicas com destino a Manaus e vice-versa.

Duas questões centrais emergira das descobertas deste estudo: a primeira foi a necessidade de se medir a elasticidade-preço dos serviços de transportes; a segunda, apontar as características diferenciadoras dos níveis de serviços de transportes de passageiros na região. A intenção é responder perguntas do tipo até que ponto a redução na tarifa dos serviços de transportes considerados superiores atrai os usuários dos serviços de transportes populares? Quais são os atributos dos diferentes níveis de serviços de transportes de passageiros praticados pelas embarcações amazônicas? 


\section{Q Bibliografía}

» Bastos, G. A. N. \& Fasolo, L. R. (2013). Fatores que influenciam a satisfação do paciente ambulatorial em uma população de baixa renda: um estudo de base populacional. Rev. Bras. Epidemiol., 16(1), p. 114-24. DOI: http://dx.doi. org/10.1590/S1415-790X2013000100011.

»Beckhauser, S. P. R. et al. (2018). Qualidade de serviços em saúde: uma avaliação em laboratórios gerais de uma cidade localizada no sul do Brasil. Revista de Estudos Sociais, Cuiabá, 20(40), 127-141.

" Costa, A. C. et al. (2018). Satisfação dos pacientes com doença de chagas atendidos por um serviço de atenção farmacêutica no estado do Ceará, Brasil. Ciência \& Saúde Coletiva, 23(5), 1483-1494. DOI: http://dx.doi.or g/10.1590/1413-81232018235.10982016.

»Dallazen, C. et al. (2018). Introdução de alimentos não recomendados no primeiro ano de vida e fatores associados em crianças de baixo nível socioeconômico. Cadernos de Saúde Pública, 34 (2), 1-13. DOI: http://dx.doi. org/10.1590/0102-311x00202816.

》Esperidião, M. A. \& Trad, L. A. B. (2006). Avaliação de satisfação de usuários: considerações teórico-conceituais. Cad. Saúde Pública, 22(6), 1267-1276. DOI: http://dx.doi.org/10.1590/S0102-311X2006000600016.

»Ferreira, A. M. (2004). Gestão da satisfação e fidelidade ao cliente: um estudo dos fatores que influenciam a satisfação e a fidelidade no turismo regional. Dissertação (Mestrado em Engenharia de Produção). Universidade Federal do Rio Grande do Norte, Natal.

" Godinho, L. A. C. et al. (2018). Avaliação empírica de um modelo de antecedentes da lealdade dos clientes no setor varejista farmacêutico. Revista de Administração da UFSM, 11(1), 135-152. DOI: http://dx.doi.org/10.5902/19834659 15510.

» González, M. O. A. (2005). Gestão de satisfação e fidelidade do cliente na hotelaria: um estudo sobre os fatores que influenciam a satisfação e a fidelidade do turista internacional no Brasil. Dissertação (Mestrado em Engenharia de Produção). Universidade Federal do Rio Grande do Norte, Natal.

» Krüger, G. N. (2018). Estudo dos fatores que afetam a lealdade dos consumidores brasileiros de ferramentas on-line de reserva hoteleira. Mestrado (Engenharia de Produção). Universidade Federal do Rio Grande do Norte, Natal.

» Lima, A. P. S., Silva, C. M., \& Romani, J. C. P. (2017). Marketing na fisioterapia: uma visão do empreendedor. Cadernos de Escola da Saúde, 1(9), 187-198.

» Lizote, S. A., Verdinelli, M. A., \& Nascimento, S. (2017). Relação do comprometimento organizacional e da satisfação no trabalho de funcionários públicos municipais. Revista de Administração Pública, 51(6), 947-967. DOI: http://dx.doi.org/10.1590/0034-7612156382.

»Martins, G. M. (2018). O relacionamento com o cliente como diferencial competitivo de clínicas veterinárias da cidade de Chapecó-SC. Mestrado (Gestão e Desenvolvimento Regional). Universidade Estadual do Oeste do Paraná, Francisco Beltrão.

" Mondo, T. S., Hallmann, G., \& Burg, O. (2018). A qualidade de serviços em dois bairros turísticos de Florianópolis-SC Brasil: um estudo com o uso do Tourqual. Revista Iberoamericana de Turismo - RITUR, 8(1), 4-16. 
» Oliveira, W. A., Sales, L. C. S., \& Brandão, E. C. (2017). Avaliação da satisfação dos usuários no atendimento das unidades de pronto atendimento (UPA) 24 horas do município de Valparaíso de Goiás-GO. Revista de Saúde da Faciplac, 4(1), 27-35.

» Nascimento, E. P., \& Costa, H. A. (2019). Turismo e Sustentabilidade: verso e reverso. Garamond, Rio de Janeiro.

»Pereira, A. F. et al. (2018). Satisfação de estudantes universitários de educação física com experiências acadêmicas. Motrivivência, 30(53), 84-100. DOI: https:// doi.org/10.5007/2175-8042.2018v30n53p84.

"Pereira, S. A. R. (2017). Saliência dos papéis e satisfação com os papéis de vida: a influência da percepção do apoio organizacional numa amostra de trabalhadoresestudantes. Dissertação (Mestrado em Psicologia). Universidade de Lisboa, Lisboa.

»Rodrigues, A. M. M. (2017). A avaliação e a opinião na gestão de desempenho: outro olhar. Tese (Doutorado em Psicologia). Instituto Universitário de Ciências Psicológicas, Sociais e da Vida, Lisboa.

» Rodrigues, J. M. S. (2003). Gestão da satisfação e da fidelidade de consumidores: um estudo dos fatores que afetam a satisfação e a fidelidade no mercado de turismo. Dissertação (Mestrado em Engenharia de Produção). Universidade Federal do Rio Grande do Norte, Natal.

"Santos, J. C. L. (2017). Uma análise dos fatores antecedentes da confiança dos cidadãos no executivo municipal. Métodos e Pesquisa em Administração, 2(1), 4-15.

» Santos, M. A., Sardinha, A. H. L., \& Santos, L. N. (2017). Satisfação dos usuários com os cuidados dos enfermeiros. Rev Gaúcha Enferm., 38(1), 1-7. DOI: http:// dx.doi.org/10.159o/1983-1447.2017.01.57506.

"Silva, J. A. et al. (2018). Análise dos registros de enfermagem após coleta de secreção traqueobrônquica para cultura: importância ética e legal. Enfermagem em Foco, 1(9), 61-65. DOI: https://doi.org/10.21675/2357-707X.2018.v9.n1.988.

»Vale A. F. N. et al. (2017). Níveis de satisfação dos discentes de administração com seus cursos e suas IES. Qualitas Revista Eletrônica, 18(2), 125-146. DOI: http:// dx.doi.org/10.18391/req.v18i2.3558.

»Vieira, A. S. T. et al. (2016). Percepção dos usuários de serviços de saúde da atenção básica no estado do Pará. Revista Brasileira de Pesquisa em Saúde, 18(3), 58-64. DOI: https://doi.org/10.21722/rbps.v18i3.15743.

"Vieira, M. J. E. (2017). Antecedentes e consequências da imagem global da marca destino: um estudo aplicado à cidade de Coimbra. Dissertação (Mestrado em Marketing). Universidade de Aveiro, Aveiro.

\section{Daniel Nascimento-e-Silva / danielnss@gmail.com}

Pós-doutorado em Administração pela Universidade Federal de Santa Catarina, Doutor em Engenharia de Produção pela Universidade Federal de Santa Catarina (UFSC), Mestre em Administração pela Universidade Federal de Santa Catarina (UFSC) e Bacharel em Administração pela Universidade Federal do Pará (UFPA). Docente do Instituto Federal de Educação, Ciência e Tecnologia do Amazonas, Campus Manaus Distrito Industrial, e do Mestrado em Educação Profissional e Tecnológica (ProfEPT).

\section{Itarciana do Rego do Rego / taciana24rego@gmail.com}

Técnica em Logística pelo Instituto Federal de Educação, Ciência e Tecnologia do Amazonas, Campus Manaus Distrito Industrial. 